\title{
Circulating Levels of Inflammatory Markers in Intrauterine Growth Restriction
}

\author{
Theodora Boutsikou, ${ }^{1}$ George Mastorakos, ${ }^{1}$ Marialena Kyriakakou, ${ }^{1}$ Alexandra Margeli, ${ }^{2}$ \\ Demetrios Hassiakos, ${ }^{1}$ Ioannis Papassotiriou, ${ }^{2}$ Christina Kanaka-Gantenbein, ${ }^{3}$ \\ and Ariadne Malamitsi-Puchner ${ }^{1}$
}

${ }^{1}$ Neonatal Division, Second Department of Obstetrics and Gynecology, University of Athens, 11528 Athens, Greece

${ }^{2}$ Department of Clinical Biochemistry, "Aghia Sophia" Children's Hospital, 11527 Athens, Greece

${ }^{3}$ First Department of Pediatrics, University of Athens, 11527 Athens, Greece

Correspondence should be addressed to Ariadne Malamitsi-Puchner, amalpu@aretaieio.uoa.gr

Received 31 October 2009; Revised 25 February 2010; Accepted 24 March 2010

Academic Editor: Hidde Bult

Copyright ( 2010 Theodora Boutsikou et al. This is an open access article distributed under the Creative Commons Attribution License, which permits unrestricted use, distribution, and reproduction in any medium, provided the original work is properly cited.

We aimed to investigate possible alterations in circulating levels of the perinatal stress markers high sensitivity (hs)-CRP, PAI-1, and S100B_-probably reflecting brain and adipose tissue inflammation-in intrauterine growth-restricted-(IUGR) and appropriatefor-gestational-age-(AGA) pregnancies, given that these groups differ in fat mass and metabolic mechanisms involving aseptic inflammation. Serum hs-CRP, PAI-1, and S100B levels were measured in 40 mothers, and their 20 AGA and 20 IUGR fullterm fetuses and neonates on postnatal days 1 and 4. hs-CRP, PAI-1, and S100B levels did not differ at all time points between AGA and IUGR groups. We conclude that the lack of difference in hs-CRP, PAI-1 and S100B levels, between IUGR and AGA fetuses/neonates_-despite the lower birth weight, reflecting reduced fat mass in the former-might indicate more intense adipose tissue and nervous system inflammation in IUGRs. However, implication of other inflammation-related mechanisms, common in the IUGR state (e.g. preeclampsia), cannot be excluded.

\section{Introduction}

Intrauterine growth restriction (IUGR), a major cause of infant mortality and morbidity $[1,2]$, is strongly related to the later development of the metabolic syndrome in adult life [3-5]. The metabolic syndrome represents a cluster of cardiovascular risk factors, such as visceral obesity, lipid and glucose metabolism abnormalities, leading to type 2 diabetes mellitus and arterial hypertension [6]. Insulin resistance has been proposed to be the underlying pathogenic link between metabolic syndrome and cardiovascular disease [7-9] and is associated with a state of low-grade aseptic inflammation that precedes the onset of metabolic syndrome $[10,11]$. Data suggest that, compared with appropriate for gestational age (AGA) newborns, those with low birth weight may have relatively increased visceral fat stores $[12,13]$, as well as elevated levels of adipocytokines, such as leptin [14-16] and visfatin [17], which link the adipose depot to insulin resistance and sensitivity, respectively, as well as to aseptic inflammation [18].

C-reactive protein (CRP) is considered the major acutephase reactant in humans. It is an important first-line host defence molecule, which recognises pathogens and damaged cells and promotes their elimination by activating the complement system and mediating their phagocytic clearance $[19,20]$. Moreover, using high-sensitivity assays for CRP (hs-CRP), several studies have shown elevated CRP levels in obesity, since adiposity resembles a low grade systemic inflammatory state and hs-CRP is released by adipose tissue $[21,22]$.

Plasminogen activator inhibitor-1 (PAI-1), secreted by vascular cells, is the primary physiological inhibitor of plasminogen activation in blood, contributing to thrombus formation [23]. It either promotes or prevents vascular remodelling processes, such as neointima formation, atherosclerosis, and pulmonary hypertension [24]. In 
addition, PAI-1 is produced by adipose tissue [25-27] and macrophages infiltrating it [28] and contributes to obesityrelated insulin resistance [25].

$\mathrm{S} 100 \mathrm{~B}$ is an acidic calcium-binding protein mainly concentrated in the central nervous system [29]. It has been reported to regulate several cellular functions (cell growth, cell structure, and energy metabolism) at physiologic concentrations, whereas it has been shown to be neurotoxic in high concentrations [30]. Elevated S100B levels have been shown to represent a marker of brain damage and hypoxicischemic encephalopathy in asphyxiated infants [31-34], thus possibly reflecting brain and central nervous system inflammation.

Based on the above, we hypothesized that circulating levels of hs-CRP, PAI-1 and S100B-all markers implicated in perinatal stress physiology_probably reflecting brain and adipose tissue inflammation, might differ in IUGR compared with AGA pregnancies. Therefore, we aimed to determine their levels at time-points characteristic for intraand extrauterine life.

\section{Materials and Methods}

2.1. Subjects. The study was approved by the Ethics Committee of our teaching hospital and informed consent was obtained from participating mothers. Forty parturients giving consecutively birth either to 20 AGA or 20 asymmetric IUGR full-term singleton infants were recruited. Gestational age was estimated using the date of the last menstrual period and early antenatal ultrasound. Birth weight was measured with an electronic scale. Newborns below the third customized centile for birth weight were defined as IUGR. For the calculation of the customized centiles, the principles of the Gestation-Related Optimal Weight (GROW) program $[35,36]$ were used. Significant determinants of birth weight (maternal height and booking weight, ethnicity, parity, gestational age and gender) were entered to adjust the normal birth weight centile limits [35].

In the IUGR group, five cases resulted from preeclampsia and seven from pregnancy-induced hypertension. In the remaining eight cases, the cause of IUGR was unclear; however, parturients suffered from chronic diseases (anaemia, type 1 diabetes mellitus, cardiac arrhythmias, and thyroiditis). Furthermore, five of the above mothers were smoking $>10$ cigarettes/day during the whole duration of pregnancy.

Doppler studies were performed in the IUGR group every 10-15 days, starting from the 32nd gestational week. During each Doppler velocimetry evaluation, three consecutive measurements of the pulsatility index (PI) of the studied vessel (uterine, umbilical, cerebral arteries) were done and the mean value was recorded. Concerning uterine and umbilical arteries $[37,38]$, mean PI values were progressively found to be in the upper physiological limits for the corresponding gestational age in 10 cases (ranging between the 90th and the 95th percentile), while in the remaining 10 cases PI values showed increased impedance to flow, being above the 95th percentile for gestational age. Regarding middle cerebral arteries [39], Doppler studies showed resistance to be in the
TABLE 1: Demographic data of participating infants (appropriate for gestational age-AGA and intrauterine growth restricted-IUGR) and of their mothers.

\begin{tabular}{lccc}
\hline & AGA & IUGR & P value \\
& MEAN \pm SD & MEAN \pm SD & \\
\hline Maternal age (years) & $31 \pm 4$ & $31 \pm 7$ & NS \\
BMI (pre-pregnancy) & $22.0 \pm 6.1$ & $22.3 \pm 6.3$ & NS \\
Gestational age (weeks) & $38.9 \pm 1$ & $37.9 \pm 1.38$ & .016 \\
Birthweight (g) & $3167 \pm 258$ & $2377 \pm 262$ & $<.001$ \\
\hline Gender $N(\%)$ & & & NS \\
Male & $8(40)$ & $7(35)$ & \\
Female & $12(60)$ & $13(65)$ & \\
\hline Mode of delivery $N(\%)$ & & & NS \\
Vaginal delivery & $9(45)$ & $9(45)$ & \\
Elective caesarean section & $11(55)$ & $11(55)$ & \\
\hline
\end{tabular}

lower physiological limits for gestational age, indicating the initiation of blood flow redistribution process, in order to spare vital organs (brain, heart, and adrenals). Nevertheless, amniotic fluid was diminished in all IUGR cases. For the evaluation of the amniotic fluid, the largest fluid column on the vertical plane was assessed and was defined as diminished if $<2 \mathrm{~cm}$. Placental weights were reduced, ranging from 240 to $450 \mathrm{~g}$.

In the AGA group, mothers were healthy and were either non-smokers or abstained from smoking during pregnancy. Placentas were normal in appearance and weight. Tests for congenital infections were negative in all women of both groups and their offspring had no symptoms of intrauterine infection or signs of genetic syndromes. One- and fiveminute Apgar scores were $\geq 8$ in all IUGR cases and AGA controls. The demographic data of participating newborns and their mothers are listed in Table 1.

2.2. Protocol. Blood was collected from: (i) the mothers (MS) during the first stage of labor, or before receiving anesthesia in cases of elective caesarean section, (ii) the doubly clamped umbilical cords (UC-mixed arteriovenous blood), reflecting fetal state, and (iii) the neonates on postpartum day $1(\mathrm{~N} 1)$ and $4(\mathrm{~N} 4)$, characterizing transition and stabilization to extrauterine life, respectively. Plasma was separated by centrifugation and was kept frozen at $-80^{\circ} \mathrm{C}$ until assay.

2.3. Assays. Serum hs-CRP level determination was performed by fully mechanized latex-particle-enhanced immunonephelometric assays on the BN ProSpec nephelometer (Dade Behring, Siemens Healthcare Diagnostics, Liederbach, Germany). The intra- and interassay coefficients of variation (CVs) were less than $6 \%$ and $7 \%$, respectively.

PAI-1 levels were measured in citrate plasma with an enzyme-linked immunosorbent assay (Asserachrom ${ }^{\circledR}$ PAI-1, Stago, Asnieres-sur-Seine, France). The minimum detectable concentration was $1.0 \mathrm{ng} / \mathrm{mL}$. The intra- and interassay coefficients of variation were $<6.0 \%$ and $7.0 \%$, respectively. 
TABLE 2: Significant correlations among hs-CRP, PAI-1, S100B and cortisol levels in IUGR and AGA groups of the MS, UC, N1, and N4 samples.

\begin{tabular}{lcc}
\hline & IUGR & AGA \\
\hline UC PAI-1 versus maternal age & $r=0.473$, & NS \\
& $P=.041$ & \\
MS CORTISOL versus UC & $r=0.824$, & $r=0.748$, \\
CORTISOL & $P<.001$ & $P<.001$ \\
MS CORTISOL versus UC PAI-1 & $r=-0.581$, & NS \\
& $P=.011$ & \\
UC CORTISOL versus MS S100B & $r=-0.494$, & NS \\
& $P=.037$ & \\
UC CORTISOL versus UC S100B & $r=-0.598$, & NS \\
& $P=.009$ & \\
UC CORTISOL versus UC PAI-1 & $r=-0.507$, & NS \\
& $P=.038$ & \\
\hline
\end{tabular}

Serum S100B protein was analyzed with the use of the immunoluminometric assay Sangtec 100, (Sangtec Medical $\mathrm{AB}$, Bromma, Sweden) and was measured by chemiluminescence on the LIAISON ${ }^{\circledR}$ random access analyzer (DiaSorin, Saluggia, Italy). Sangtec 100 measures the $\beta$-subunit of $\mathrm{S} 100$ as defined by 3 monoclonal antibodies. The minimum detectable concentration of the assay was $0.02 \mu \mathrm{g} / \mathrm{L}$. The analysis represents the total amount of S100 and S100B in the sample, as the assay is specific for the beta-chain. The intra-and interassay coefficients of variation for S100B were less than 3.8 and $5.7 \%$, respectively.

Finally we used data concerning serum levels of the anti-inflammatory agent cortisol which were previously determined [40].

\section{Statistical Analysis}

Data distribution was tested with the Kolmogorov Smirnov test. PAI-1, hs-CRP, and S100B levels were not normally distributed, thus nonparametric procedures (Mann-Whitney test, Friedman test, Wilcoxon Sign Rank Test, Spearman Rank correlation coefficient) were applied in the analysis. $P$ values $<.05$ were considered significant.

\section{Results}

Maternal (MS), fetal (UC), day 1 (N1), and day 4 (N4) neonatal levels of inflammatory markers in IUGR cases and AGA controls are presented in Figures 1, 2, and 3.

hs-CRP levels did not differ significantly at all time points between AGA and IUGR groups. In both groups, MS hs-CRP was significantly higher than UC, N1 and N4 values $(P<$ $.001, P=.012$, and $P=.001$, resp., in the AGA group and $P<.001, P=.001$ and $P=.001$, resp., in the IUGR group). UC hs-CRP was significantly decreased when compared to $\mathrm{N} 1$ hs-CRP $(P<.001)$ in the AGA group, and to N1 and N4 hs-CRP $(P=.002$ and $P=.006$, resp., $)$ in the IUGR group.

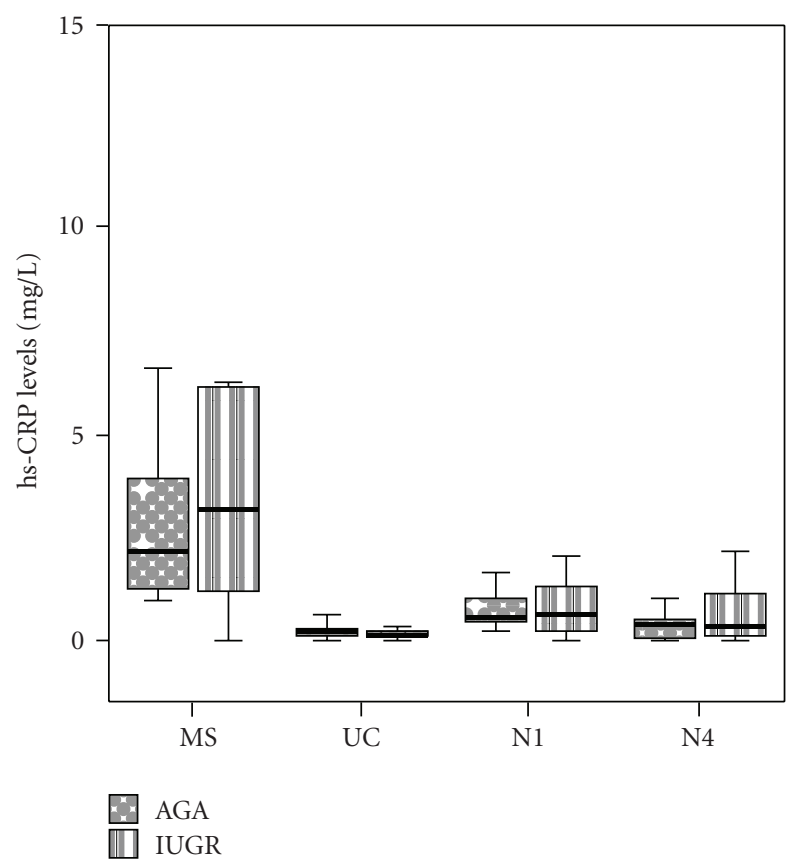

FIGURE 1: Box and whiskers plot presentation of maternal (MS), fetal (UC), neonatal day 1 (N1), and neonatal day 4 (N4) Creactive protein (hs-CRP) levels. Each box represents the median concentration with the interquartile range. The upper and lower whiskers represent the range.

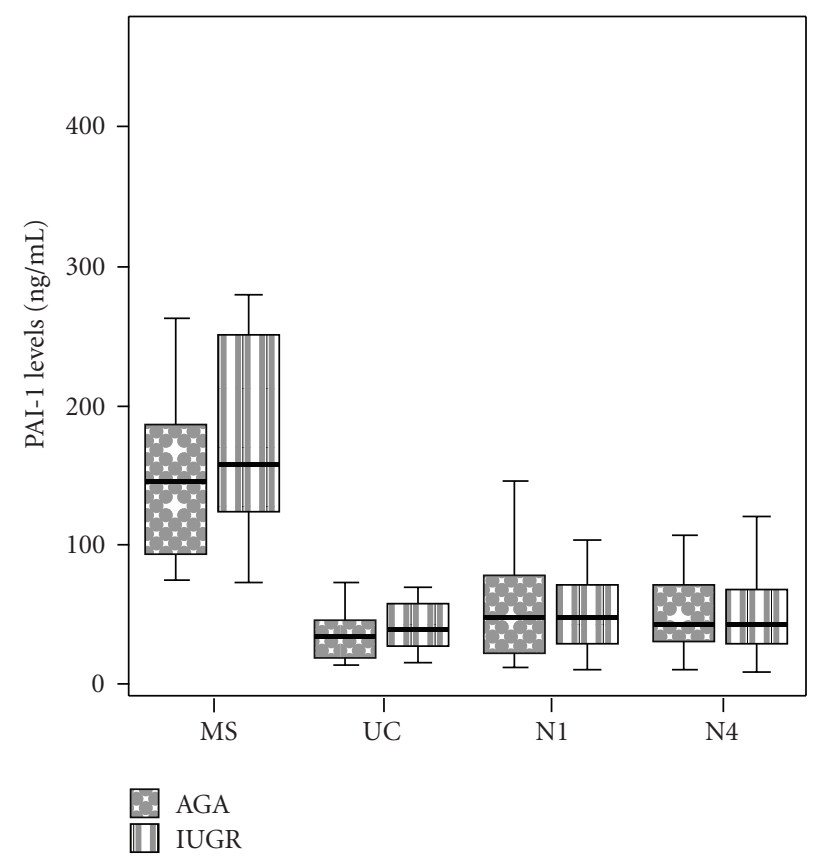

FIGURE 2: Box and whiskers plot presentation of maternal (MS), fetal (UC), neonatal day 1 (N1), and neonatal day 4 (N4) PAI1 levels. Each box represents the median concentration with the interquartile range. The upper and lower whiskers represent the range.

PAI-1 levels did not differ significantly at all time points between AGA and IUGR groups. In both groups, MS PAI-1 


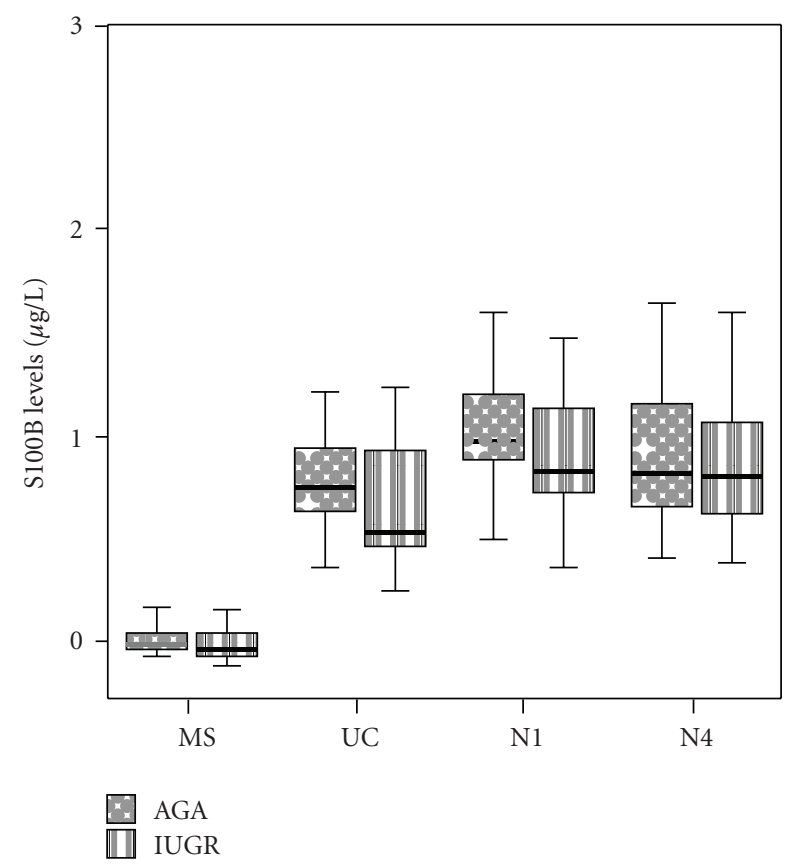

FIgURE 3: Box and whiskers plot presentation of maternal (MS), fetal (UC), neonatal day 1 (N1) and neonatal day 4 (N4) S100B levels. Each box represents the median concentration with the interquartile range. The upper and lower whiskers represent the range.

was significantly higher than UC, N1, or N4 PAI-1 $(P<$ $.001, P<.001$, and $P=.003$, resp., in the AGA and $P=.004$, $P=.001$, and $P<.001$, resp., in the IUGR group). No significant differences were observed among UC, N1 and N4 PAI-1 measurements, either in the AGA or the IUGR group.

S100B levels did not differ significantly at all time points between AGA and IUGR groups. In both groups, MS S100B was significantly lower than UC, N1 and N4 levels $(P<.001$, $P<.001$ and $P=.001$, resp., in the AGA group and $P<.001$ in all cases in the IUGR group). In both groups, N1 S100B was significantly increased when compared to respective UC S100B ( $P=.004$ for both groups).

Statistically significant correlations among inflammatory markers and cortisol at all time points in AGA and IUGR neonates and their mothers are reported in Table 2. Thus, positive correlations were documented between fetal PAI1 levels and maternal age (in the IUGR group), as well as between maternal and fetal cortisol levels (in both groups). On the other hand, negative correlations were found (in the IUGR group) between maternal cortisol and fetal PAI1 levels, as well as fetal cortisol and maternal/fetal S100B and fetal PAI-1 levels.

\section{Discussion}

The results of this study indicate that inflammatory markers, implicated in perinatal stress physiology, such as hs-CRP, PAI-1 and S100B, determined in the plasma of AGA and
IUGR mother/infant pairs at birth and on postnatal days 1 and 4 did not differ between the two studied groups.

Maternal hs-CRP levels were found significantly higher than fetal and neonatal ones in both studied groups. It has been previously shown, that maternal CRP values consistently increase throughout pregnancy as compared to the nonpregnant state, culminating during labour [41, 42]. Furthermore, it is known that CRP does not cross the placental barrier [43], justifying the significantly lower levels found in fetuses and neonates.

On the other hand, CRP is a marker of inflammation produced by adipose tissue [21]. Considering that IUGR babies have by definition lower amounts of total fat mass as compared to AGA babies, the lack of difference in CRP levels between these two groups, could suggest a more intense inflammatory state in the adipose tissue of the former. The gradual increase of CRP in both studied groups from UC to $\mathrm{N} 1$, and $\mathrm{N} 4$ could possibly be attributed to adaptational stress [44-46] to extrauterine life. CRP is produced by pulmonary alveolar macrophages (PAM), among other immune response cells [47], and studies in animals have shown the rapid increase of PAM during postnatal development [48]. Thus, it is possible that the major source of postpartum CRP production is the constantly increasing PAM population in the neonatal lung.

Furthermore, we found that in both studied groups, maternal PAI-1 levels were significantly higher than fetal and neonatal ones. Taken that adipose tissue is an important source of PAI-1 production [49], this could be attributed to its higher amounts in adults as compared to neonates.

The lack of difference in PAI-1 levels between IUGR and AGA groups could speculatively be attributed, as for CRP, to a state of more intense adipose tissue-related inflammation in the IUGR, as compared to the AGA neonates. In this respect, we have previously documented that circulating levels of the adipocytokines leptin and visfatin are relatively increased in IUGR neonates, despite their reduced total fat mass $[17,40]$. Moreover, CRP has been shown to induce PAI-1 expression [50-53]. In addition, other studies have documented that PAI-1 is mainly produced by visceral fat [49], which is proportionally higher in the IUGR than the AGA neonates [12, 13].

However, another explanation could be considered. Thus, dysfunctional vascular endothelium, characterizing preeclampsia resulting to IUGR, is associated with increased PAI-1 release [54]. In this respect, the lack of significant differences in PAI-1 levels between IUGR and AGA groups in the present study could possibly rely to the fact that only five out of 20 IUGR pregnancies were complicated by preeclampsia.

Furthermore, smoking in pregnancy, apart from being a risk factor for IUGR [55], has a deleterious effect on vascular endothelium, resulting in endothelial dysfunction, which again is associated with PAI-1 production [56]. The fact that PAI-1 levels were similar in both groups of this study could be attributed to the limited number of IUGR mothers smoking during pregnancy.

In both groups, maternal S100B levels were significantly lower than fetal and neonatal ones (N1 and N4), while 
N1 S100B levels were significantly higher than respective UC ones. S100B has a neurotrophic effect during both development and nerve regeneration [57-59]. Respectively, Gazzolo et al. documented higher S100B concentrations in children during the first year of life and in adolescence, as compared to adults, thus documenting its neurotrophic role [57]. This fact might explain on one hand, the low S100B levels in mothers, and on the other, the gradual increase of S100B levels from N1 to N4.

The lack of significant differences in the levels of S100B between the two studied groups in the three perinatal time points could possibly be attributed to the brainsparing phenomenon in cases of IUGR that ensures nutrient supply to vital organs $[60,61]$. Thus, glial cells, mainly producing S100B, remain unaffected by malnutrition [57]. Alternatively, Florio et al. documented increased levels of S100B in urine samples from IUGR neonates, with highest levels in those with abnormal neurological outcome [62]. Indeed, S100B is also a marker of hypoxia-induced brain damage [29, 62]. Nevertheless, the IUGR group in this study consisted of asymmetrical IUGR babies, with good Apgar scores at birth and no neurologic sequelae in the short term, whatsoever.

Furthermore, this study showed that in the IUGR group, UC PAI-1 positively correlated with maternal age. Previous studies $[63,64]$ have reported significantly higher placental PAI-1 levels in IUGR pregnancies with or without preeclampsia. Taken that older gravidas are at increased risk of IUGR pregnancies complicated by preeclampsia and abnormal placentation [65], the above finding could be justified.

On the other hand, controversial reports in the literature also associate very young maternal age groups with preeclampsia [66-72]. Nevertheless, the present study did not comprise in the IUGR group such individuals, since the age range of the included mothers was 24-38 years.

The positive correlation of maternal and fetal cortisol levels found in both groups of our study is probably due to placental transfer $[73,74]$.

As cortisol has a well-known anti-inflammatory effect, the negative correlations of MS cortisol with UC PAI-1, as well as UC cortisol with MS S100B, UC S100B, and UC PAI-1 in the IUGR group (Table 2), further enhance the hypothesis for the inflammation-mediating role of S100B and PAI1. Besides, studies have also documented the reduction of S100B in the presence of corticosteroids $[75,76]$.

In conclusion, the absence of difference in hs-CRP and PAI-1 levels, between IUGR cases and AGA controls, possibly indicates an accentuated secretion of these markers from the adipose tissue in the former, who despite their lower birth weight, bear a relatively increased amount of visceral fat as compared to the latter. On the other hand, the lack of difference in S100B levels between these two groups possibly reflects the brain-sparing effect occurring in IUGR cases. Moreover, cortisol remains a major antiinflammatory compound that counteracts the effect of the above mentioned inflammatory markers. Thus, our findings could probably support the concept of aseptic inflammation in IUGR fetuses and neonates. However, implication of other inflammation-related mechanisms, common in the IUGR state (e.g. preeclampsia) cannot be excluded.

\section{References}

[1] D. Brodsky and H. Christou, "Current concepts in intrauterine growth restriction," Journal of Intensive Care Medicine, vol. 19, no. 6, pp. 307-319, 2004.

[2] S. Sankaran and P. M. Kyle, "Aetiology and pathogenesis of IUGR," Best Practice and Research: Clinical Obstetrics and Gynaecology, vol. 23, no. 6, pp. 765-777, 2009.

[3] N. B. Metcalfe and P. Monaghan, "Compensation for a bad start: grow now, pay later?" Trends in Ecology and Evolution, vol. 16, no. 5, pp. 254-260, 2001.

[4] D. A. Leon, I. Koupilova, H. O. Lithell, et al., "Failure to realise growth potential in utero and adult obesity in relation to blood pressure in 50 year old Swedish men," British Medical Journal, vol. 312, no. 7028, pp. 401-406, 1996.

[5] J. G. Eriksson, T. Forsén, J. Tuomilehto, P. D. Winter, C. Osmond, and D. J. P. Barker, "Catch-up growth in childhood and death from coronary heart disease: longitudinal study," British Medical Journal, vol. 318, no. 7181, pp. 427-431, 1999.

[6] D. J. Rader, "Effect of insulin resistance, dyslipidemia, and intra-abdominal adiposity on the development of cardiovascular disease and diabetes mellitus," American Journal of Medicine, vol. 120, no. 3, supplement 1, pp. S12-S18, 2007.

[7] G. Reaven, "Why a cluster is truly a cluster: insulin resistance and cardiovascular disease," Clinical Chemistry, vol. 54, no. 5, pp. 785-787, 2008.

[8] J. B. Meigs, M. K. Rutter, L. M. Sullivan, C. S. Fox, R. B. D'Agostino Sr., and P. W. F. Wilson, "Impact of insulin resistance on risk of type 2 diabetes and cardiovascular disease in people with metabolic syndrome," Diabetes Care, vol. 30, no. 5, pp. 1219-1225, 2007.

[9] G. M. Reaven, "Banting lecture 1988. Role of insulin resistance in human disease," Diabetes, vol. 37, no. 12, pp. 1595-1607, 1988.

[10] K. Park, M. Steffes, D.-H. Lee, J. H. Himes, and D. R. Jacobs Jr., "Association of inflammation with worsening HOMA-insulin resistance," Diabetologia, vol. 52, no. 11, pp. 2337-2344, 2009.

[11] R. Deepa, K. Velmurugan, K. Arvind, et al., "Serum levels of interleukin 6, C-reactive protein, vascular cell adhesion molecule 1 , and monocyte chemotactic protein 1 in relation to insulin resistance and glucose intolerance-the Chennai Urban Rural Epidemiology Study (CURES)," Metabolism, vol. 55, no. 9, pp. 1232-1238, 2006.

[12] C. S. Yajnik, "Early life origins of insulin resistance and type 2 diabetes in India and other Asian countries," Journal of Nutrition, vol. 134, no. 1, pp. 205-210, 2004.

[13] C. S. Yajnik, H. G. Lubree, S. S. Rege, et al., "Adiposity and hyperinsulinemia in Indians are present at birth," Journal of Clinical Endocrinology and Metabolism, vol. 87, no. 12, pp. 5575-5580, 2002.

[14] M. Otero, R. Lago, F. Lago, et al., "Leptin, from fat to inflammation: old questions and new insights," FEBS Letters, vol. 579, no. 2, pp. 295-301, 2005.

[15] M. Lappas, M. Permezel, and G. E. Rice, "Leptin and adiponectin stimulate the release of proinflammatory cytokines and prostaglandins from human placenta and maternal adipose tissue via nuclear factor- $\kappa \mathrm{B}$, peroxisomal proliferator-activated receptor- $\gamma$ and extracellularly regulated kinase 1/2," Endocrinology, vol. 146, no. 8, pp. 3334-3342, 2005. 
[16] A. Mostyn, D. H. Keisler, R. Webb, T. Stephenson, and M. E. Symonds, "The role of leptin in the transition from fetus to neonate," Proceedings of the Nutrition Society, vol. 60, no. 2, pp. 187-194, 2001.

[17] A. Malamitsi-Puchner, D. D. Briana, M. Boutsikou, E. Kouskouni, D. Hassiakos, and D. Gourgiotis, "Perinatal circulating visfatin levels in intrauterine growth restriction," Pediatrics, vol. 119, no. 6, pp. e1314-e1318, 2007.

[18] B. Antuna-Puente, B. Feve, S. Fellahi, and J.-P. Bastard, "Adipokines: the missing link between insulin resistance and obesity," Diabetes and Metabolism, vol. 34, no. 1, pp. 2-11, 2008.

[19] R. F. Mortensen, "C-reactive protein, inflammation, and innate immunity," Immunologic Research, vol. 24, no. 2, pp. 163-176, 2001.

[20] T. W. Du Clos, "Function of C-reactive protein," Annals of Medicine, vol. 32, no. 4, pp. 274-278, 2000.

[21] N. Ouchi, S. Kihara, T. Funahashi, et al., "Reciprocal association of C-reactive protein with adiponectin in blood stream and adipose tissue," Circulation, vol. 107, no. 5, pp. 671-674, 2003.

[22] U. N. Das, "Is obesity an inflammatory condition?" Nutrition, vol. 17, no. 11-12, pp. 953-966, 2001.

[23] W. P. Fay, N. Garg, and M. Sunkar, "Vascular functions of the plasminogen activation system," Arteriosclerosis, Thrombosis, and Vascular Biology, vol. 27, no. 6, pp. 1231-1237, 2007.

[24] I. Diebold, D. Kraicun, S. Bonello, and A. Görlach, "The 'PAI-1 paradox' in vascular remodelling," Thrombosis and Haemostasis, vol. 100, no. 6, pp. 984-991, 2008.

[25] M.-C. Alessi, M. Poggi, and I. Juhan-Vague, "Plasminogen activator inhibitor-1, adipose tissue and insulin resistance," Current Opinion in Lipidology, vol. 18, no. 3, pp. 240-245, 2007.

[26] D. Bastelica, P. Morange, B. Berthet, et al., "Stromal cells are the main plasminogen activator inhibitor-1-producing cells in human fat: evidence of differences between visceral and subcutaneous deposits," Arteriosclerosis, Thrombosis, and Vascular Biology, vol. 22, no. 1, pp. 173-178, 2002.

[27] J. N. Fain, A. K. Madan, M. L. Hiler, P. Cheema, and S. W. Bahouth, "Comparison of the release of adipokines by adipose tissue, adipose tissue matrix, and adipocytes from visceral and subcutaneous abdominal adipose tissues of obese humans," Endocrinology, vol. 145, no. 5, pp. 2273-2282, 2004.

[28] R. Cancello, C. Henegar, N. Viguerie, et al., "Reduction of macrophage infiltration and chemoattractant gene expression changes in white adipose tissue of morbidly obese subjects after surgery-induced weight loss," Diabetes, vol. 54, no. 8, pp. 2277-2286, 2005.

[29] D. Gazzolo, E. Marinoni, R. Di Iorio, et al., "Measurement of urinary S100B protein concentrations for the early identification of brain damage in asphyxiated full-term infants," Archives of Pediatrics and Adolescent Medicine, vol. 157, no. 12, pp. 1163-1168, 2003.

[30] C. W. Heizmann, "Ca ${ }^{2+}$-binding $\mathrm{S} 100$ proteins in the central nervous system," Neurochemical Research, vol. 24, no. 9, pp. 1097-1100, 1999.

[31] D. Gazzolo, R. Di Iorio, E. Marinoni, et al., "S100B protein is increased in asphyxiated term infants developing intraventricular hemorrhage," Critical Care Medicine, vol. 30, no. 6, pp. 1356-1360, 2002.

[32] D. Gazzolo, M. Bruschettini, M. Lituania, G. Serra, E. Gandullia, and F. Michetti, "S100B protein concentrations in urine are correlated with gestational age in healthy preterm and term newborns," Clinical Chemistry, vol. 47, no. 6, pp. 1132-1133, 2001.

[33] D. Gazzolo, E. Marinoni, R. Di Iorio, et al., "Urinary S100B protein measurements: a tool for the early identification of hypoxic-ischemic encephalopathy in asphyxiated full-term infants," Critical Care Medicine, vol. 32, no. 1, pp. 131-136, 2004.

[34] D. Gazzolo, M. Bruschettini, M. Lituania, G. Serra, W. Bonacci, and F. Michetti, "Incresed urinary S100B protein as an early indicator of intraventricular hemorrhage in preterm infants: correlation with the grade of hemorrhage," Clinical Chemistry, vol. 47, no. 10, pp. 1836-1838, 2001.

[35] J. Gardosi, A. Chang, B. Kalyan, D. Sahota, and E. M. Symonds, "Customised antenatal growth charts," Lancet, vol. 339, no. 8788, pp. 283-287, 1992.

[36] J. Gardosi, M. Mongelli, M. Wilcox, and A. Chang, "An adjustable fetal weight standard," Ultrasound in Obstetrics \& Gynecology, vol. 6, no. 3, pp. 168-174, 1995.

[37] P. Kaminopetros, M. T. Higueras, and K. H. Nicolaides, "Doppler study of uterine artery blood flow: comparison of findings in the first and second trimesters of pregnancy," Fetal Diagnosis and Therapy, vol. 6, no. 1-2, pp. 58-64, 1991.

[38] G. Acharya, T. Wilsgaard, G. K. R. Berntsen, J. M. Maltau, and T. Kiserud, "Reference ranges for serial measurements of umbilical artery Doppler indices in the second half of pregnancy," American Journal of Obstetrics and Gynecology, vol. 192, no. 3, pp. 937-944, 2005.

[39] A. A. Baschat, H. L. Galan, A. Bhide, et al., "Doppler and biophysical assessment in growth restricted fetuses: distribution of test results," Ultrasound in Obstetrics and Gynecology, vol. 27, no. 1, pp. 41-47, 2006.

[40] M. Kyriakakou, A. Malamitsi-Puchner, H. Militsi, et al., "Leptin and adiponectin concentrations in intrauterine growth restricted and appropriate for gestational age fetuses, neonates, and their mothers," European Journal of Endocrinology, vol. 158, no. 3, pp. 343-348, 2008.

[41] L. Belo, A. Santos-Silva, S. Rocha, et al., "Fluctuations in Creactive protein concentration and neutrophil activation during normal human pregnancy," European Journal of Obstetrics Gynecology and Reproductive Biology, vol. 123, no. 1, pp. 46$51,2005$.

[42] D. H. Watts, M. A. Krohn, M. H. Wener, and D. A. Eschenbach, "C-reactive protein in normal pregnancy," Obstetrics and Gynecology, vol. 77, no. 2, pp. 176-180, 1991.

[43] F. R. Nielsen, K. M. Bek, P. E. Rasmussen, I. Qvist, and M. Tobiassen, "C-reactive protein during normal pregnancy," European Journal of Obstetrics Gynecology and Reproductive Biology, vol. 35, no. 1, pp. 23-27, 1990.

[44] C. Chiesa, F. Signore, M. Assumma, et al., "Serial measurements of C-reactive protein and interleukin-6 in the immediate postnatal period: reference intervals and analysis of maternal and perinatal confounders," Clinical Chemistry, vol. 47, no. 6, pp. 1016-1022, 2001.

[45] M. Ishibashi, Y. Takemura, H. Ishida, K. Watanabe, and T. Kawai, "C-reactive protein kinetics in newborns: application of a high-sensitivity analytic method in its determination," Clinical Chemistry, vol. 48, no. 7, pp. 1103-1106, 2002.

[46] E. Mathai, U. Christopher, M. Mathai, A. K. Jana, D. Rose, and S. Bergström, "Is C-reactive protein level useful in differentiating infected from uninfected neonates among those at risk of infection?" Indian Pediatrics, vol. 41, no. 9, pp. 895-900, 2004. 
[47] Q. Dong and J. R. Wright, "Expression of C-reactive protein by alveolar macrophages," Journal of Immunology, vol. 156, no. 12, pp. 4815-4820, 1996.

[48] R. Dickie, D. R. Tasat, E. F. Alanis, V. Delfosse, and A. Tsuda, "Age-dependent changes in porcine alveolar macrophage function during the postnatal period of alveolarization," Developmental and Comparative Immunology, vol. 33, no. 2, pp. 145-151, 2009.

[49] D. Bastelica, P. Morange, B. Berthet, et al., "Stromal cells are the main plasminogen activator inhibitor-1-producing cells in human fat: evidence of differences between visceral and subcutaneous deposits," Arteriosclerosis, Thrombosis, and Vascular Biology, vol. 22, no. 1, pp. 173-178, 2002.

[50] V. Pasceri, J. T. Willerson, and E. T. H. Yeh, "Direct proinflammatory effect of C-reactive protein on human endothelial cells," Circulation, vol. 102, no. 18, pp. 2165-2168, 2000.

[51] V. Pasceri, J. Chang, J. T. Willerson, and E. T. H. Yeh, "Modulation of C-reactive protein-mediated monocyte chemoattractant protein-1 induction in human endothelial cells by antiatherosclerosis drugs," Circulation, vol. 103, no. 21, pp. 25312534, 2001.

[52] S. Verma, S.-H. Li, M. V. Badiwala, et al., "Endothelin antagonism and interleukin-6 inhibition attenuate the proatherogenic effects of C-reactive protein," Circulation, vol. 105, no. 16, pp. 1890-1896, 2002.

[53] S. Devaraj, D. Y. Xu, and I. Jialal, "C-reactive protein increases plasminogen activator inhibitor-1 expression and activity in human aortic endothelial cells: implications for the metabolic syndrome and atherothrombosis," Circulation, vol. 107, no. 3, pp. 398-404, 2003.

[54] S. Guller, Y. Y. Ma, H.-H. Fu, G. Krikun, V. M. Abrahams, and G. Mor, "The placental syncytium and the pathophysiology of preeclampsia and intrauterine growth restriction: a novel assay to assess syncytial protein expression," Annals of the New York Academy of Sciences, vol. 1127, pp. 129-133, 2008.

[55] C. Salafia and K. Shiverick, "Cigarette smoking and pregnancy. II: vascular effects," Placenta, vol. 20, no. 4, pp. 273-279, 1999.

[56] A. E. Quinton, C.-M. Cook, and M. J. Peek, "The relationship between cigarette smoking, endothelial function and intrauterine growth restriction in human pregnancy," British Journal of Obstetrics and Gynaecology, vol. 115, no. 6, pp. 780784, 2008.

[57] D. Gazzolo, F. Michetti, M. Bruschettini, et al., "Pediatric concentrations of $\mathrm{S} 100 \mathrm{~B}$ protein in blood: age- and sex-related changes," Clinical Chemistry, vol. 49, no. 6, pp. 967-970, 2003.

[58] K. G. Haglid, Q. Yang, A. Hamberger, S. Bergman, A. Widerberg, and N. Danielsen, "S-100 $\beta$ stimulates neurite outgrowth in the rat sciatic nerve grafted with acellular muscle transplants," Brain Research, vol. 753, no. 2, pp. 196-201, 1997.

[59] F. Michetti and D. Gazzolo, "S100B protein in biological fluids: a tool for perinatal medicine," Clinical Chemistry, vol. 48, no. 12, pp. 2097-2104, 2002.

[60] C. N. Hales and D. J. P. Barker, "Type 2 (non-insulindependent) diabetes mellitus: the thrifty phenotype hypothesis," Diabetologia, vol. 35, no. 7, pp. 595-601, 1992.

[61] C. N. Hales and D. J. P. Barker, "The thrifty phenotype hypothesis," British Medical Bulletin, vol. 60, pp. 5-20, 2001.

[62] P. Florio, E. Marinoni, R. Di Iorio, et al., "Urinary S100B protein concentrations are increased in intrauterine growthretarded newborns," Pediatrics, vol. 118, no. 3, pp. e747-e754, 2006.

[63] A. Estellés, J. Gilabert, M. Keeton, et al., "Altered expression of plasminogen activator inhibitor type 1 in placentas from pregnant women with preeclampsia and/or intrauterine fetal growth retardation," Blood, vol. 84, no. 1, pp. 143-150, 1994.

[64] B. L. Sheppard and J. Bonnar, "Uteroplacental hemostasis in intrauterine fetal growth retardation," Seminars in Thrombosis and Hemostasis, vol. 25, no. 5, pp. 443-446, 1999.

[65] A. O. Odibo, D. Nelson, D. M. Stamilio, H. M. Sehdev, and G. A. Macones, "Advanced maternal age is an independent risk factor for intrauterine growth restriction," American Journal of Perinatology, vol. 23, no. 5, pp. 325-328, 2006.

[66] K. Duckitt and D. Harrington, "Risk factors for pre-eclampsia at antenatal booking: systematic review of controlled studies," British Medical Journal, vol. 330, no. 7491, pp. 565-567, 2005.

[67] E. J. Kongnyuy, P. N. Nana, N. Fomulu, S. C. Wiysonge, L. Kouam, and A. S. Doh, "Adverse perinatal outcomes of adolescent pregnancies in Cameroon," Maternal and Child Health Journal, vol. 12, no. 2, pp. 149-154, 2008.

[68] I. M. Usta, D. Zoorob, A. Abu-Musa, G. Naassan, and A. H. Nassar, "Obstetric outcome of teenage pregnancies compared with adult pregnancies," Acta Obstetricia et Gynecologica Scandinavica, vol. 87, no. 2, pp. 178-183, 2008.

[69] M. H. Aliyu, S. Luke, S. Kristensen, A. P. Alio, and H. M. Salihu, "Joint effect of obesity and teenage pregnancy on the risk of preeclampsia: a population-based study," Journal of Adolescent Health, vol. 46, no. 1, pp. 77-82, 2010.

[70] T. O. Lawoyin and F. A. Ani, "Epidemiologic aspects of preeclampsia in Saudi Arabia," East African Medical Journal, vol. 73, no. 6, pp. 404-406, 1996.

[71] H. S. Ros, S. Cnattingius, and L. Lipworth, "Comparison of risk factors for preeclampsia and gestational hypertension in a population-based cohort study," American Journal of Epidemiology, vol. 147, no. 11, pp. 1062-1070, 1998.

[72] C.-J. Lee, T.-T. Hsieh, T.-H. Chiu, K.-C. Chen, L.-M. Lo, and T.-H. Hung, "Risk factors for pre-eclampsia in an Asian population," International Journal of Gynecology and Obstetrics, vol. 70, no. 3, pp. 327-333, 2000.

[73] A. Clerico, M. G. Del Chicca, M. Ferdeghini, S. Ghione, and F. Materazzi, "Progressively elevated levels of biologically active (free) cortisol during pregnancy by a direct radioimmunological assay of diffusible cortisol in an equilibrium dialysis system," Journal of Endocrinological Investigation, vol. 3, no. 2, pp. 185-187, 1980.

[74] M. Dalle, P. Pradier, and P. Delost, "The regulation of glucocorticosteroid secretion during the perinatal period," Reproduction Nutrition Developpement, vol. 25, no. 5, pp. 977991, 1985.

[75] M. Bruschettini, D. L. A. van den Hove, D. Gazzolo, P. Bruschettini, C. E. Blanco, and H. W. M. Steinbusch, "A single course of antenatal betamethasone reduces neurotrophic factor S100B concentration in the hippocampus and serum in the neonatal rat," Developmental Brain Research, vol. 159, no. 2, pp. 113-118, 2005.

[76] D. L. A. Van den Hove, H. W. M. Steinbusch, M. Bruschettini, et al., "Prenatal stress reduces $\mathrm{S} 100 \mathrm{~B}$ in the neonatal rat hippocampus," NeuroReport, vol. 17, no. 10, pp. 1077-1080, 2006. 


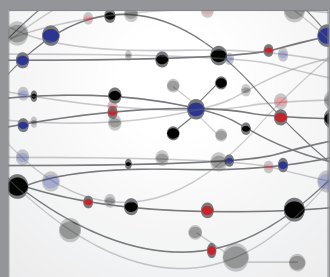

The Scientific World Journal
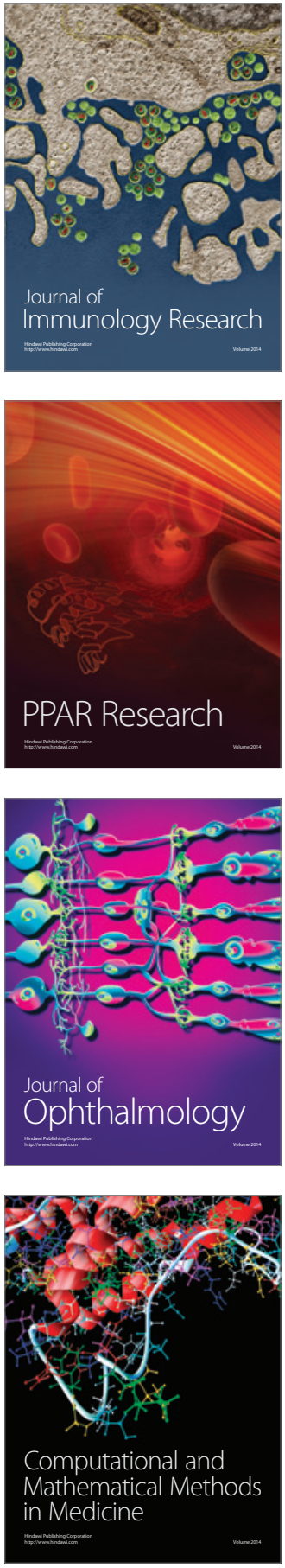

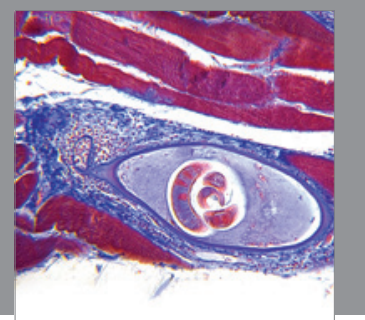

Gastroenterology

Research and Practice
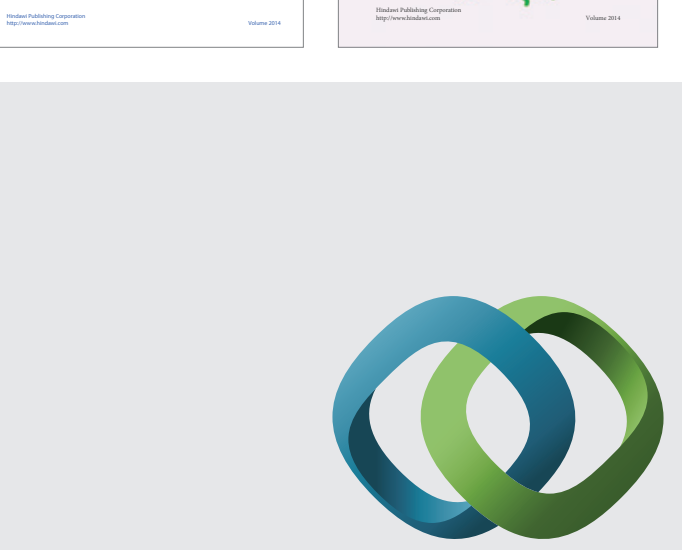

\section{Hindawi}

Submit your manuscripts at

http://www.hindawi.com
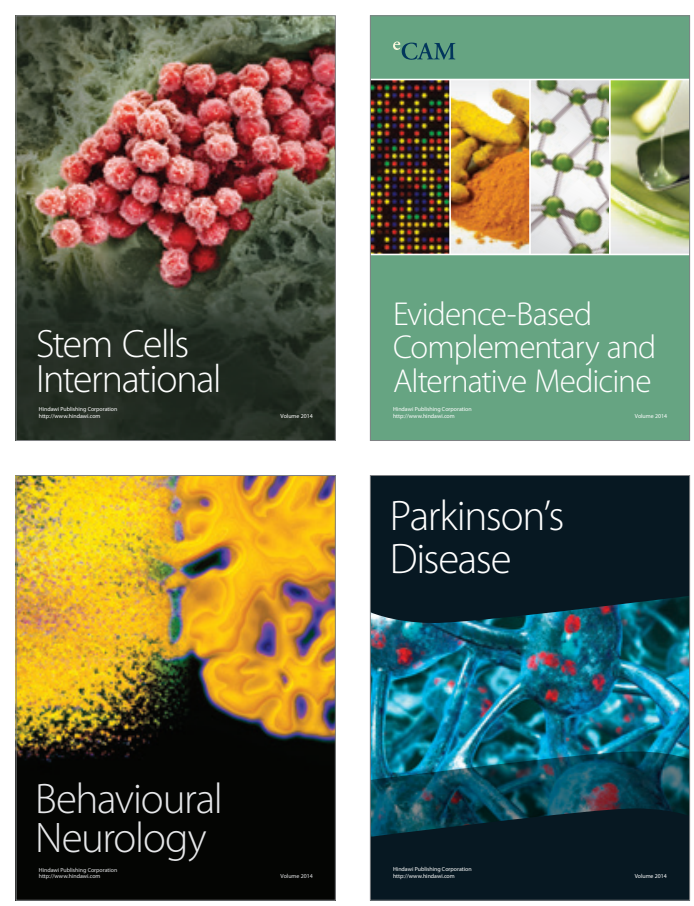

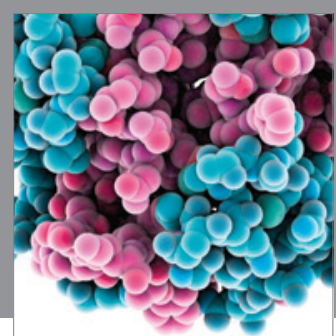

Journal of
Diabetes Research

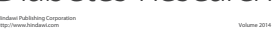

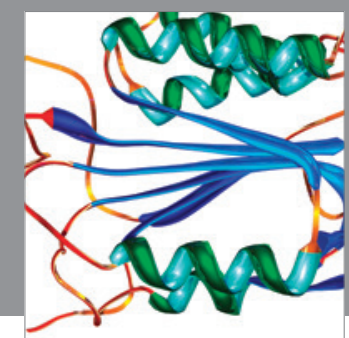

Disease Markers
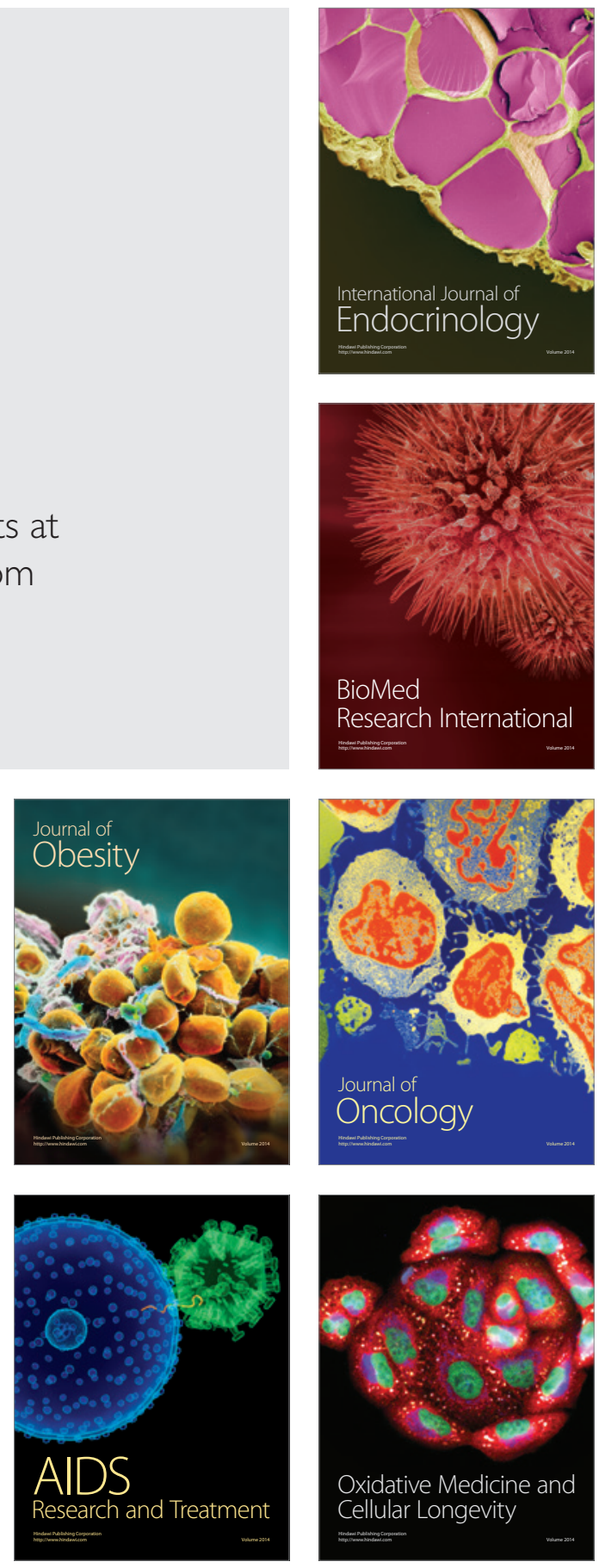